\title{
Mycotoxicological and palynological profiles of commercial brands of dried bee pollen
}

\author{
Michele Valadares Deveza ${ }^{1}$, Kelly Moura Keller ${ }^{2}$, Maria Cristina Affonso Lorenzon ${ }^{3}$, \\ Lucila Maria Teixeira Nunes ${ }^{4}$, Érika Oliveira Sales ${ }^{5}$, Ortrud Monika Barth ${ }^{5}$ \\ ${ }^{1}$ Instituto de Veterinária, Universidade Federal Rural do Rio de Janeiro, Seropédica, RJ, Brazil. \\ ${ }^{2}$ Departamento de Medicina Veterinária Preventiva, Universidade Federal de Minas Gerais, \\ Belo Horizonte, MG, Brazil. \\ ${ }^{3}$ Departamento de Produção Animal, Universidade Federal Rural do Rio de Janeiro, \\ Seropédica, RJ, Brazil. \\ ${ }^{4}$ Instituto de Agronomia, Universidade Federal Rural do Rio de Janeiro, Seropédica, RJ, Brazil. \\ ${ }^{5}$ Instituto Oswaldo Cruz, Fiocruz, Rio de Janeiro, RJ, Brazil.
}

Submitted: April 15, 2014; Approved: March 5, 2015.

\begin{abstract}
Pollen is used in the human diet as a food supplement because of its high nutritional value; however, this product is prone to fungal contamination that could potentially generate toxins that are harmful to human health. This study aimed to verify the floral diversity of commercial brands of bee pollen and their mycotoxicological safety for human consumption. A total of 27 bee pollen samples were analyzed; these samples represented commercial brands, either showing an inspection seal or not, marketed in the State of Rio de Janeiro. The analyzed parameters included floral diversity through palynological analysis, water activity, fungal counts, identification and toxigenic profiles. The palynological analysis identified nine plant families, of which the Asteraceae was predominant. Analysis of hygienic quality based on fungal load showed that $92 \%$ of samples were reproved according to the commercial, sanitary, and food safety quality indicators. Aspergillus, Cladosporium and Penicillium were the most common genera. Toxigenic evaluation showed that $25 \%$ of the A. flavus strains produced aflatoxins. The high rate of contamination of products bearing an inspection seal emphasizes the need to monitor the entire procedure of bee pollen production, as well as to revise the current legislation to ensure safe commercialization of this product.
\end{abstract}

Key words: bee products, fungi, mycotoxins, pollen loads, public health.

\section{Introduction}

Honeybees (Apis mellifera) forage pollen grains of specific floral species, resulting in highly agglutinated pollen loads attached to their hind legs. The bees initiate the preparation of food for the beehive by adding nectar and salivary substances to the pollen. Part of these pollen loads is collected by the beekeeper before the bees enter the beehive and is treated as bee pollen (Lengler, 2002) known as pollinic "mix." The color of the pollen grains is highly variable and reflects the diversity of the botanical species visited by the bees.
The use of bee pollen is common in the human diet. Apitherapy is the field of apicultural science that involves the treatment of diseases (Olegário et al., 2008) either through the significant content in substances of high biological value as proteins, carbohydrates, minerals, and vitamins (Abreu, 1992; Johnson and Nicolson, 2001; Carpes, 2008) or high levels of polyphenolic substances, primarily flavonoids with powerful antioxidant (Campos et al., 2003) and antimicrobial activity (Basim et al., 2006; García et al., 2001). Ishikawa et al. (2008) and Kafadar et al. (2012) demonstrated that pollen cures certain diseases. This profile has placed pollen in the list of top consumer items

Send correspondence to K.M. Keller. Departamento de Medicina Veterinária Preventiva, Escola de Veterinária, Universidade Federal de Minas Gerais, Avenida Antônio Carlos nº6627, 30123-970 Belo Horizonte, Minas Gerais, Brazil. E-mail: kelly.medvet@gmail.com. 
known for its functional and nutritional properties that offer health benefits (Kroyer and Hegedus, 2001; González et al., 2005).

Food supplements such as pollen are rich in proteins, lipids, and sugar and are thus also susceptible to rapid degradation, which in turn increases the risk for food poisoning due to fungal growth. In general, fungal contamination of food involves the presence of mycotoxins, which are products of fungal secondary metabolism (Fao, 1990). Mycotoxins are carcinogenic, mutagenic, teratogenic, nephrotoxigenic, and immunosuppressive in humans and other animals, and are responsible for global food losses amounting to billions of dollars (Kuiper-Goodman and Scott, 1996).

Dehydration is a common step in bee pollen processing that ensures quality; it prevents the growth of fungi and bacteria and improves its safety and shelf life (Brasil, 2001a). This procedure is feasible when contamination factors associated with the place of origin and hive management do not lead to high levels of contamination, which are conditions that are not always met (Barreto et al., 2006).

In Brazil, the consumer demand for bee pollen is high, which contributes to an increase in apicultural production and improves of the quality of life of farmers. On the other hand, the incidence of food contamination has increased in the fields to such a degree that Brazil is currently recognized as the highest consumer of agrochemicals. Because pollen is highly predisposed to environmental pollutants (Kalbande et al., 2008), it represents a major barrier in the apicultural chain development at the national marketing level.

In the quest to improve the quality of bee pollen production, the present study aimed to verify the floral diversity and microbiological safety of commercial brands of bee pollen for human consumption.

\section{Materials and Methods}

A total of 27 samples of dried bee pollen marketed in major commercial establishments in the State of Rio de Janeiro were acquired. Two brands were from the State of São Paulo, three brands from Minas Gerais, one brand from Paraná, and the remainder were from the State of Rio de Janeiro. Most brands featured an inspection seal; 10 of these showed a State seal, whereas 12 showed a Federal seal. Five samples were collected as informal products (products marketed without any kind of inspection).

Pollen analysis of the samples were performed in the Laboratory of Morphology and Viral Morphogenesis at the Oswaldo Cruz Institute, Fiocruz (Rio de Janeiro/Brazil). Two grams of dried pollen were homogenized in $70 \%$ alcohol, subjected to ultrasonic bath for $5 \mathrm{~min}$, and centrifuged. These samples were washed in water and water-glycerin, mounted on slides with gelatin-glycerin in duplicate, sealed with paraffin, and used for qualitative evaluation.
Mycological and mycotoxicological analyses were performed at the Núcleo de Pesquisas Micológicas e Micotoxicológicas of the Universidade Federal Rural do Rio de Janeiro. Initially, water activity $\left(A_{w}\right)$ was determined using the AquaLab ${ }^{\circledR}$ equipment (CX 2 model, Decagon Devices Inc., USA). Samples showing water activity of $<0.60$ were considered stable and classified as dehydrated (Labuza, 1980).

Mycobiota determination was performed by counting the number of filamentous fungi in colony-forming units occurring per gram of food $\left(\mathrm{cfu} \mathrm{g}^{-1}\right)$ after serial dilution plating (Pitt and Hocking, 1997). For each sample, $1 \mathrm{~mL}$ aliquots of each of the four dilutions were inoculated (in triplicate) in three culture media: dicloran bengal rose chloramphenicol (DBRC) agar, which is a general purpose medium used to grow fungi isolated from foods (Pitt and Hocking, 1997); dichloran 18\% glycerol agar (DG18), a selective medium for xerophilic species such as the genera Aspergillus and Penicillium (Pitt and Hocking, 1997); and a peptone base agar and containing $0.1 \%$ pentachloronitrobenzene (PCNB), a selective medium for the genus Fusarium (NELSON et al., 1983). The plates were incubated at $25^{\circ} \mathrm{C}$ for 5 to 7 days under controlled temperature. All plates were observed daily, and those containing between 10 and $100 \mathrm{cfu} \mathrm{g}^{-1}$ were selected for counting. The limit of $100 \mathrm{cfu} \mathrm{g}^{-1}$ used in the determination of hygienic quality in honey (Brasil, 1997) and royal jelly (Brasil, 2001a) was adopted to assess the degree of contamination of the samples. This value was based on the fact that these products are consumed in natura and in small portions. The resolution RDC No. 12 revoked the ordinance on microbiological criteria (Brasil, 2001b), which are considered mandatory parameters for the evaluation of bee pollen.

Fungal colonies of Aspergillus and Penicillium were subcultivated in slanted tubes containing malt extract agar (MEA), whereas Fusarium colonies were cultivated in banana leaf agar (BLA). The identification of Aspergillus sp. was conducted according to Klich (2002), that for Penicillium sp. was based on Pitt (1988), and that for Fusarium sp. was according to Nelson et al. (1983). To characterize the toxigenic profile, strains of Aspergillus sections Flavi and Nigri were analyzed according to Geisen (1996) and Bragulat et al. (2001), respectively.

Shelf life evaluation was only performed on samples bearing an inspection seal using the sell-by date and date of purchase information.

\section{Results}

Most of the samples of the pollen products that showed an inspection seal did not present any changes in color and odor, and no fungi were observed at the time of their receipt in the laboratory. Only one sample (without an inspection seal) showed caramelized pollen with an intense brown color. 
Analysis of the floral sources of the samples revealed 12 pollen types belonging to nine plant families (Table 1); six types belonged to the predominant class of pollen. The Asteraceae type was the predominant class (26\%), which was observed in 13 out of the 27 samples. On the other hand, the Amaranthaceae, Apiaceae, and Solanaceae types were observed as isolated pollen. In terms of floral diversity, $65 \%$ of the products showed only one floral source (in the class of predominant pollen), whereas the remaining presented a composition originating from two to four pollen types (in the class of accessory pollen). Samples from the State of São Paulo were mainly of the Cecropia (embaúba) and Cocos nucifera (coqueiro) pollen types, those from Minas Gerais consisted of Brassica and Mimosa, whereas those from Rio de Janeiro were of Eucalyptus, Brassica, Mimosa, Cocos nucifera and the pollen types of Myrcia and Asteraceae, and Paraná from Mimosa and the Asteraceae type. Close to $50 \%$ of the samples were derived from crops, and most of the pollen types were represented in small amounts, comprising eight types of accessory pollen and nine types of isolated pollen.

The fungal contamination load in the culture media was variable, at a level of $5.0 \times 10^{2} \mathrm{cfu} \mathrm{g}^{-1}$ in the DBRC media, $2.0 \times 10^{2} \mathrm{cfu} \mathrm{g}^{-1}$ in the DG18 media, and $1.0 \times 10^{2} \mathrm{cfu}$ $\mathrm{g}^{-1}$ in the PCNB media. The values obtained in the DBRC and DG18 media did not meet the legal standards described in the ordinance SVS/MS No. 451 (Brasil, 1997). The brands that failed represented $89 \%$ of the samples with a state seal (SIE), $92 \%$ with a federal seal (SIF), and 100\% of the informal products (without an inspection seal). The inspection seals showed a low variation in fungal contamination.
The water activity of the bee pollen samples was low, with a median value of 0.404 and a mean of $0.393(0.056$; the minimum and maximum values were 0.287 and 0.489 , respectively. Although the development of most microorganisms responsible for food spoilage is inhibited by $\mathrm{A}_{\mathrm{w}}<0.90$, the high fungal contamination observed in the bee pollen samples indicated that contamination occurs even in low humidity conditions.

Because most of the products included in the study had a shelf life of 2 years, contamination was verified for all brands (Table 2), including one sample with a shelf life of 3 years.

A high diversity of the mycobiota was observed in the bee pollen samples. Seventy-seven strains belonging to 10 filamentous genera were isolated. Aspergillus was the predominant $(85 \%)$ isolated fungal species, followed by Cladosporium (63\%), Penicillium (41\%), Alternaria (19\%), Wallemia and Eurotium (11\%), Mucor (7\%), Curvularia, Paecilomyces and Fusarium (4\%).

Among the Aspergillus isolates, the highest relative density was observed in $A$. niger aggregates (39\%), followed by $A$. flavus (21\%), A. fumigatus (18\%), $A$. versicolor (11\%); A. ochraceus, $A$. carbonarius, $A$. terreus and $A$. oryzae $(3 \%)$ were also detected. For the genus Penicillium, $P$. citrinum and $P$. citreonigrum were the predominant species (50\% and 33\%, respectively); P. glabrum and $P$. oxalicum (8\%) were also detected. Fusarium camptoceras was the only representative of the genus Fusarium.

The toxigenic profiles were negative for $A$. niger aggregates, A. ochraceus, and $A$. carbonarius strains, which are potentially producers of ochratoxin A. Twenty-five percent of the $A$. flavus strains were positive for the production

Table 1 - Frequency of pollen types present in dehydrated apiarian pollen according to sample content and plant family.

\begin{tabular}{|c|c|c|c|c|}
\hline \multirow[t]{2}{*}{ Pollen types } & \multirow[t]{2}{*}{ Total frequency ${ }^{1}$} & \multicolumn{3}{|c|}{ Frequency of pollen types ${ }^{2}$} \\
\hline & & Predominantly & Accessory & Isolated \\
\hline Asteraceae & $26 \%(13)$ & $23 \%$ & $46 \%$ & $31 \%$ \\
\hline Amaranthaceae-Amaranthus & $4 \%(2)$ & $0 \%$ & $0 \%$ & $100 \%$ \\
\hline Apiaceae & $4 \%(2)$ & $0 \%$ & $0 \%$ & $100 \%$ \\
\hline Caesalpiniaceae-Caesalpinia type & $4 \%(2)$ & $0 \%$ & $100 \%$ & $0 \%$ \\
\hline Mimosaceae - Mimosa caesalpiniaefolia & $4 \%(2)$ & $0 \%$ & $50 \%$ & $50 \%$ \\
\hline Mimosa scabrella & $6 \%(3)$ & $33 \%$ & $33 \%$ & $33 \%$ \\
\hline Palmae - Cocos nucifera & $14 \%(7)$ & $26 \%$ & $57 \%$ & $17 \%$ \\
\hline Cecropiaceae - Cecropia & $4 \%(2)$ & $0 \%$ & $50 \%$ & $50 \%$ \\
\hline Brassicaceae - Brassica & $14 \%(7)$ & $43 \%$ & $43 \%$ & $14 \%$ \\
\hline Myrtaceae - Myrcia type & $10 \%(5)$ & $20 \%$ & $20 \%$ & $60 \%$ \\
\hline Eucalyptus sp. & $8 \%(4)$ & $75 \%$ & $0 \%$ & $25 \%$ \\
\hline Solanaceae - Solanum & $2 \%(1)$ & $0 \%$ & $0 \%$ & $100 \%$ \\
\hline
\end{tabular}

${ }^{1}$ Number of samples.

${ }^{2}$ Frequency calculated as a function of each plant family. 
Table 2 - Relationship between shelf life and fungal load of the dried bee pollen samples marketed in the State of Rio de Janeiro.

\begin{tabular}{lc}
\hline Shelf life (years) & DRBC cfu ${ }^{-1}$ (minimum and maximum) \\
\hline 1 & $6 \times 10^{1}-8 \times 10^{4}$ \\
2 & $1 \times 10^{1}-2 \times 10^{4}$ \\
3 & $5 \times 10^{2}-5 \times 10^{3}$ \\
\hline
\end{tabular}

of aflatoxins $\mathrm{B}_{1}$ and $\mathrm{B}_{2}$ in in vitro conditions (qualitative data).

\section{Discussion}

The diversity of the Brazilian flora has triggered the extensive production of hetero-floral honey and pollen (Freitas et al., 2013). Despite this fact, commercial bee pollen manufactured in Rio de Janeiro mainly originated from monocultures, similar to coconut and Eucalyptus cultivation. The occurrence of brands produced from wildlife pollen types, Asteraceae, Mimosaceae and Brassicaceae is highlighted next to the figures of hetero-floral pollen. The floral diversity decreased in each brand due to the presence of floral species, which are effective suppliers of bee pollen, and varied according to the region surrounding the apiary and climatic conditions during blooming.

Microbiological analysis showed that the marketed products are not within the established legal standards (Brasil, 1997, 2001b) of a maximum of $100 \mathrm{cfu} \mathrm{g}^{-1}$ of fungi and yeasts. Among all studied samples, 93\% showed unsatisfactory conditions or were unsuitable for direct human consumption due to the presence of high fungal activity and possibly mycotoxigenic action (Cast, 2003). Other studies on bee pollen in the market of Bahia, Brasília-DF, Minas Gerais, Paraná, Rio Grande do Sul, Santa Catarina, São Paulo and Sergipe have also detected high microbiological contamination $\left(>1,3 \times 10^{4} \mathrm{cfu} \mathrm{g}^{-1}\right)$ in at least $12 \%$ of the analyzed products (Barreto, 2004).

The findings of this study also suggest that Federal and State surveillance measures might have also been ineffective in reducing product contamination, with informal products showing higher levels of contamination. The high fungal and toxigenic load detected in the samples raises questions on how contamination occurs during its production and pollen collection (Barreto et al., 2006). It is also possible that contamination may be present during storage.
Because tropical conditions could affect the quality of food in natura, there is a predisposition for pollen samples to present greater mycobiota diversity (Table 3 ).

Aspergillus is the predominant genus isolated in previous studies listed in Table 4. Aspergillus parasiticus is one of the main producers of aflatoxins (González et al., 2005). Its presence has not been detected in Brazilian samples.

Cladosporium is the second most common genus isolated from commercial pollen products. Modro et al. (2009) reported the Cladosporium sp. collection by bees at an apiary characterized by high air relative humidity and low availability of food resources (pollen and nectar). The nutritional composition of the fungi pellets presented high protein value, ethereal extract and organic matter and could be used as a resource for the brood.

Penicillium is the third most common genus isolated from commercial pollen products, although previous findings showed variable results. González et al. (2005) reported that it is the most prevalent genus, whereas Villalobos et al. (2010) described it as the fifth most isolated genus. Fusarium was rarely detected in the present study, which was similar to the results of González et al. (2005) and Villalobos et al. (2010)

The toxigenic results of the present study support those of González et al. (2005), who analyzed samples from Spain and Argentina, except those involving OTA production by the $A$. ochraceus and $A$. niger aggregates strains, which was not detected in our samples. Pollen stimulates the production of OTA under A. ochraceus growth (Medina et al., 2004; Villalobos et al., 2010), which was not verified in our samples. The mycotoxin production depends on a series of factors such as humidity, temperature, oxygen availability, fungi growth time, substrate composition, quantity of fungi inoculum, as well as the interaction/competition among fungi strains (Cast, 2003) which could explain this variability on results.

Contamination of bee pollen compromises its consumption based on its risk to human health. Despite the severity of this matter, the Brazilian legislation for bee pollen was not defined based on physicochemical limits nor does it contemplate the limits for microbiological contamination or water activity. The National Health Surveillance Agency (Anvisa) regulations do not even treat this product as a food item.

Table 3 - Fungi isolated from commercial pollen samples according to the country of origin.

\begin{tabular}{lc}
\hline Country of origin & Isolated mycobiota \\
\hline Brasil Aspergillus, Cladosporium, Penicillium, Alternaria, Wallemia, Eurotium, Mucor, \\
Curvularia, Paecilomyces, Fusarium
\end{tabular}


Table 4 - Aspergillus species isolated from commercial pollen samples originating from various countries.

\begin{tabular}{lcc}
\hline Country of origin & Aspergillus species & Authors \\
\hline Brasil & A. niger aggregates, A. flavus, A. versicolor, A. ochraceus, A. oryzae, A. terreus, & This study \\
Argentina and Spain & A. niger aggregates, A. flavus, A. ochraceus, A. parasiticus & González et al. (2005) \\
Mexico & A. flavus & Villalobos et al. (2010) \\
\hline
\end{tabular}

Therefore, the Brazilian legislation that identifies the item as a component of "other apiculture products" (Normative Instruction 3, from January 19, 2001), which includes bee pollen (in addition to propolis, royal jelly, apitoxin, and beeswax) requires revision to address the growth of apiculture production each year. The main function of the standard is to establish the parameters and technical requirements for food safety of products and processes, certification of the industry organization, protection of their products against any technical restrictions, and compliance to market demands (Camargo, 2008). Despite the small number of samples of the present study, it is clear that if the terms of legislation for this food are weak, the production of low-quality products can arise.

It should also be highlighted that the decline in the quality of the product could be due to the negligence of beekeepers in adopting of hygienic standards and proper handling of the product in one or more stages of production, which may result in products that could be harmful to human health (Vasconcelos, 2009). The timing of pollen harvest might also be a critical factor because these items are not collected daily because of the distance between apiaries and processing sites. Storage of collected pollen prior to processing and packaging also exposes the raw materials to moisture in the air. Pollen with high levels of lipids such as those of several Asteraceae species thus serve as optimal substrates for fungal growth compared to pollen with lower lipid content (Cecropiaceae). Another phase that requires caution is dehydration; this step should be performed in a facility with controlled temperature and immediately after collection. Toxigenic fungi present in pollen can grow and produce mycotoxins if the period between harvest and dehydration is too long. Furthermore, these toxins remain in the bee pollen even after heat exposure during drying.

Cast (2003) and Rodriguez et al. (2008) have suggested that the entire process of bee pollen production should be reviewed, from collection to storage, to minimize its risks to human health. Martins et al. (2013) have suggested that pollen be identified as a food or supplement, and that the allowable limits of contaminants be established. The improvement in management techniques is another important factor of efficient and safe beekeeping (Fachini et al., 2010). Thus, producers must promote changes based on the findings of published reports.

\section{Conclusions}

There is currently a high demand for bee pollen in Brazil, which has resulted in its increased production and in turn requires systematization of the beekeeping business. There is also a serious problem relating to the hygienicsanitary quality of marketed dried bee pollen in the State of Rio de Janeiro. The present study has detected high fungal contaminations, significantly higher than the established microbiological standards for foods. Fungi produce mycotoxins that cause mycotoxicosis in humans. Microbiological analyses represent an important tool in screening the hygiene conditions of the environment and the production process of food. The same guidelines should be implemented for pollen. There is a need to revise the legislation for this product and increase the surveillance on the quality of pollen for human consumption.

\section{Acknowledgments}

The authors would like to thank the Conselho Nacional de Desenvolvimento Científico e Tecnológico (CNPq) and the Pró-Reitoria de Pesquisa da Universidade Federal de Minas Gerais (PRPq-UFMG) for its financial support, and also the active participation of the Coordination of Defense and Health Inspection of the State of Rio de Janeiro.

\section{References}

Abreu M (1992) El polen como alimento en la nutrición humana. Alimentaria 29:45-46.

Barreto LMRC (2004) Pólen Apícola Brasileiro: Perfil da Produção, Qualidade e Caracterização Organoléptica. PhD Thesis, Faculdade de Medicina Veterinária e Zootecnia, Botucatu.

Barreto LMRC, Funari SRC, Orsi RO et al. (2006) Produção do Pólen no Brasil. Cabral Editora, Taubaté.

Basim E, Basim H, Özcan M (2006) Antibacterial activities of Turkish pollen and propolis extracts against plant bacterial pathogens. J Food Eng 77:992-996.

Bragulat MR, Abarca ML, Cabañes FJ (2001) An easy screening method for fungi producing ochratoxin A in pure culture. Int J Food Microbiol 71:139-144.

Brasil (199) Agência Nacional de Vigilância Sanitária - Anvisa Portaria n ${ }^{\circ}$ 451, 19 set 1997.

Brasil (2001a) Ministério da Agricultura e Abastecimento - Mapa Instrução Normativa n 3, 19 jan 2001.

Brasil (2001b) Agência Nacional de Vigilância Sanitária - Anvisa Resolução RDC n 12, 02 jan 2001. 
Campos MG, Webby RF, Markham KR et al. (2003) Age-induced diminution of free radical scavenging capacity in bee pollens and the contribution of constituent flavonoids. J Agr Food Chem 51:742-745.

Carpes ST (2008) Estudo das características físico-químicas e biológicas do pólen apícola de Apis mellifera $\mathrm{L}$. da região sul do Brasil. Universidade Federal do Paraná, Curitiba (Thesis).

Camargo RCR (2008) Normalização na cadeia produtiva apícola nacional. Rev Mensagem Doce 96 Available at: http://www.apacame.org.br. Accessed 25 fev 2009.

CAST - Council for Agricultural Science and Technology (2003) Micotoxins: risks in plant, animal and humans systems. Task Force Report n ${ }^{\circ}$ 139, USA.

FAO (1990) Training in Mycotoxin Analysis Manuals of Food Quality Control. FAO, Rome.

Fachini C, Firetti R, Oliveira EC et al. (2010) Perfil da apicultura em Capão Bonito, Estado de São Paulo: aplicação da análise multivariada. Rev Econom Agric 57:49-60.

Freitas AS, Arruda VAS, Almeida-Muradian LB et al. (2013) The botanical profiles of dried bee pollen loads collected by Apis mellifera (Linnaeus) in Brazil. Sociobiology 60:56-64.

García M, Pérez-Arquillue C, Juan T et al. (2001) Pollen analysis and antibacterial activity of Spanish honeys. Food Sci Technol Int 7:155-158.

Geisen R (1996) Multiplex polymerase chain reaction for the detection of potential aflatoxin and sterigmatocystin producing fungi. Syst Appl Microbiol 19:388-392.

González G, Hinojo MJ, Mateo R et al. (2005) Ocurrence of mycotoxin producing fungi in bee pollen. Int $\mathrm{J}$ Food Microbiol 105:1-9.

Ishikawa Y, Tokura T, Nakano N et al. (2008) Inhibitory effect of honeybee-collected pollen on mast cell degranulation in vivo and in vitro. J Med Food 11:14-20.

Johnson SA, Nicolson SW (2001) Pollen digestion by flowerfeeding Scarabaeidae: protea beetles (Cetoniini) and monkey beetles (Hopliini). J Insect Physiol 47:725-733.

Labuza TP (1980) The effect of water activity on kinectics of food deterioration. Food Technol 39:36-41.

Kafadar IH, Güney A, Türk CY et al. (2012) Royal jelly and bee pollen decrease bone loss due to osteoporosis in an oophorectomized rat model. Eklem Hastalik Cerrahisi 23:100-105.

Kalbande DM, Dhadse SN, Chaudhari PR et al. (2008) Biomonitoring of heavy metals by pollen in urnan environment. Environ Monit Assess 138:233-238.
Klich MA (2002) Identification of Common Aspergillus Species. Centraalbureau voor Schimmelcultures, Netherlands.

Kroyer G, Hegedus N (2001) Evaluation of bioactive properties of pollen extracts as functional dietary food supplement. Innov Food Sci Emerg Tech 2:171-174.

Kuiper-Goodman T, Scott PM (1996) Risk assessment of the mycotoxin ochratoxin A: an update. Food Addit Contam 13:53-57.

Lengler S (1999) Pólen Apícola. UFSM, Rio Grande do Sul.

Martins MCT, Rodriguez-Amaya DB, Morgano MA (2013) Pólen Apícola na Alimentação Humana. FUNEP, São Paulo.

Medina A, González G, Sáez JM et al. (2004) Bee pollen, a substrate that stimulates ochratoxin A production by Aspergillus ochraceus Wilh. Syst Appl Microbiol 27:261-267.

Modro AFH, Silva IC, Message D et al. (2009) Saprophytic Fungus Collection by Africanized Bees in Brazil. Neotrop Entomol 38:434-436.

Nelson PE, Toussoun TA, Marasas WFO (1983) Fusarium Species: An Illustrated Manual for Identification. The Pennsylvania State University Press.

Olegário TG, Santos JT, Trindade JLF (2008) Pólen: propriedades nutricionais e benefícios à saúde humana. Available at: http://www.pg.utfpr.edu.br/setal/docs/artigos/2008/a1/014. pdf Accessed 15 jan 2011.

Pitt JI (1988) A Laboratory Guide to Commom Penicillium Species. CSIRO, Australia.

Pitt JI, Hocking AD (1997) Fungi and Food Spoilage. Chapman \& Hall, Cambridge.

Rodriguez MAA, Keller KM, Keller LAM et al. (2008) Avaliação micológica e micotoxicológica do pólen da abelha jataí (Tetragonisca angustula) proveniente de Ilha Grande, Angra dos Reis, Rio de Janeiro Rev Bras Med Vet 30:249-253.

Vasconcelos MRS (2009) Pólen Apícola do Estado de Alagoas: Composição Físico-Química, Origem Botânica e Atividade Antioxidante. PhD Thesis, Universidade Federal de Alagoas.

Villalobos CMB, Preciado GL, Jaime OAM et al. (2010) Mycoflora asociated to bee pollen collected by domesticated bees (Apis mellifera L). Rev Electronic Nova Scientia 2:93-103.

Associate Editor: Susana Marta Isay Saad

All the content of the journal, except where otherwise noted, is licensed under a Creative Commons License CC BY-NC. 